EPiC Series in Built Environment
Volume 1, 2020, Pages 178-186
$\begin{gathered}\text { Associated Schools of Construction Proceed- } \\ \text { ings of the 56th Annual International Conference }\end{gathered}$

\title{
Graduate Construction Management Education: A Senior-level, Industry-Based Delphi Study
}

\author{
Ravi Teja Pathuri, MS, John Killingsworth, Ph.D. and Chris Harper, Ph.D. \\ Colorado State University \\ Fort Collins, Colorado
}

\begin{abstract}
Graduate education can be utilized by working professionals as an advancement to their careers. This paper presents the results of a Delphi survey sent to 31experts in the construction industry. A survey questionnaire was developed to ask the participants about their perceptions of the relevance of the current graduate-level construction management courses in developing senior-level construction managers. A curriculum analysis of 34 graduate CM programs in the United States was conducted. The resulting data from the curriculum analysis is utilized in developing the survey questionnaire. The study is part of a larger research Delphi study that aimed at identifying the Knowledge, Skills, and Abilities required for senior-level managers in the construction industry. Two phases of the survey were sent to participants in this Delphi study. The results of the study indicate that the current graduate programs in construction management across the United States of America are not adequately focused on developing senior-level construction managers.
\end{abstract}

Key Words: Construction Executives, Delphi Study, Construction Management Education, Senior-level management

\section{Introduction}

The construction industry is quick-paced and constantly evolving (Arditi \& Polat, 2010). To address the emerging issues in construction, senior-level managers are continuously required to develop new strategies for effective decision making. The increasing complexity of the construction projects, advances in project management strategies, and the evolution of new technologies increased the demand for construction managers who are well-trained and well-educated in the knowledge of building and business management (Atalah \& Muchemedzi, 2006). Due to the increased demand for construction managers, many engineering professionals are enrolling in graduate construction management programs to further their education (Atalah \& Muchemedzi, 2006). The current graduate programs in construction management are not adequately focused on developing advanced 
management and leadership skills. The study conducted by (Goodman \& Chinowsky, 1997) found that professionals who received advanced degrees in traditional Construction Management (CM) programs are clearly not meeting the demands of the industry. The authors define senior-level construction management focused programs as the programs which help and prepare mid-level construction managers in advancing their skill-sets to reach a senior-level position. Graduate education can be utilized by working professionals as an advancement to their careers. Recognizing that limited research had been reported which identified the relevance of the current graduate construction management curriculums in developing senior-level construction management leaders, the current research was undertaken. This study is a part of a larger research study that aims at identifying the Knowledge, Skills, and Abilities (KSAs) required for senior-level managers in the construction industry. The long-term research objective of the authors was to influence curriculum development for programs serving senior-level managers in the construction industry.

\section{Construction Education: History and Trends}

Construction education in the United States derives its history from the 1920s. Until the 1920s, there were very few Civil Engineering programs in the United States which offered a specialization in Construction, particularly Construction Management. Universities started developing CM graduate programs during the mid-1970s (Arditi \& Polat, 2010; Atalah \& Muchemedzi, 2006). By the start of the 1980s, there were more than 40 graduate CM programs in existence across the United States. Some masters-level programs focused on developing qualified professionals for CM consulting firms, while most focused on developing research faculty (Arditi \& Polat, 2010).

To understand the emphasis of the current graduate CM programs, this study examined a majority of the construction management graduate programs in the United States. Currently, there are 76 undergraduate $\mathrm{CM}$ programs and four graduate $\mathrm{CM}$ programs in the United States, which have been accredited by the American Council for Construction Education (ACCE). Looking at just those four graduate programs would not be a sufficient sample size to reach any conclusions regarding the focus of current graduate CM programs. Therefore, this study also considered the non-accredited CM graduate programs offered by the universities with accredited CM undergraduate programs for curriculum analysis. The official websites of these universities were accessed, and the authors found that 34 universities of the selected programs have been offering a graduate program in construction. This translates to $45 \%$ of the US universities offering ACCE accredited undergraduate CM programs.

These 34 graduate CM programs offer a total of 463 courses. Research work or thesis was excluded from the curriculum analysis. The average number of courses per program is 13.62 . The course data for all the programs was obtained through the course catalog descriptions in the respective program websites. The 20 most frequently offered courses in these programs were evaluated for content and are listed in Table 1. The courses having similar content were grouped into a single course or topic category. The frequency represents the percentage of programs offering that course. The ranking is based on the frequency of the course offerings.

Note that only two of the 20 frequent courses were offered in more than $50 \%$ of the programs. Not a single course or topic is offered in more than $70 \%$ of the programs. This supports the findings of (Popescu, 1987) that there is a greater variation within the graduate-level CM curriculums. The 34 graduate programs differ in the types of degree offered. The different types of degrees offered include Master of Science in Construction Management or Construction Engineering Management, Master of Construction Management, and MBA in CM. 
Table 1

Courses offered at the graduate level Construction Management programs in the U.S.

\begin{tabular}{|c|c|c|}
\hline Courses/ Topics & Frequency $(\%)$ & Ranking \\
\hline Sustainability and Green Construction & 62 & 1 \\
\hline Construction Project Management & 56 & 2 \\
\hline Construction Cost Estimation/Bidding Strategy & 44 & 3 \\
\hline Construction Management Research & 44 & 4 \\
\hline Construction Scheduling & 44 & 5 \\
\hline Construction Accounting \& Finance & 41 & 6 \\
\hline Construction Law & 41 & 7 \\
\hline Construction Contracts Administration/Business & 32 & 8 \\
\hline Construction Planning and Cost Control/Analysis & 29 & 9 \\
\hline Construction Safety Management & 26 & 10 \\
\hline Construction Project Delivery Systems & 24 & 11 \\
\hline Graduate Internship & 24 & 12 \\
\hline Independent Study & 24 & 13 \\
\hline Seminar & 24 & 14 \\
\hline Advanced Computer Applications in Construction & 18 & 15 \\
\hline Construction Management Special Topics & 21 & 16 \\
\hline Leadership in Construction & 21 & 17 \\
\hline Building Information Modeling & 18 & 18 \\
\hline Construction Visualization and Simulation & 18 & 19 \\
\hline Legal Issues in Construction & 18 & 20 \\
\hline
\end{tabular}

Since the purpose of the current study was to find the relevance of the graduate-level CM courses in developing senior-level construction managers, the authors looked for the programs which had a focus on developing leaders. First, the authors categorized the 34 programs into two categories. The two categories are i) programs with Leadership and Upper-level construction management focus and ii) programs with Research and Technical skills focus. To categorize the programs, the authors looked at the purpose statements of those programs. The purpose statements were inspected by accessing the websites of the 34 programs. Out of the 34 universities, 16 universities mentioned that their program had an emphasis on developing leaders and upper-level construction managers, while 14 universities mentioned that their program is more research-oriented and focuses on technical skills of construction. The remaining four universities did not have any purpose statement and are excluded from the curriculum analysis. Table 2 represents the 20 most frequent courses offered by the two categories (Leadership Focused or Research Focused). The ranking in Table 2 is based on the frequency of the course offerings. There is very little difference in the courses offered, between the two categories; in fact, they have 14 courses in common. It is generally acknowledged that a Master of Science program is more research-based, which explains the apparent lack of senior management level courses. 
Table 2

Courses offered in the two categories

\begin{tabular}{|c|c|c|}
\hline Ranking & $\begin{array}{l}\text { Courses/Topics in the Leadership } \\
\text { focus programs }\end{array}$ & $\begin{array}{l}\text { Courses/Topics in the Research and } \\
\text { Technical skills focus programs }\end{array}$ \\
\hline 1 & Sustainability and Green Construction & Construction Management Research \\
\hline 2 & Construction Project Management & Sustainability and Green Construction \\
\hline 3 & $\begin{array}{l}\text { Construction Cost Estimation/Bidding } \\
\text { Strategy }\end{array}$ & Construction Project Management \\
\hline 4 & Construction Scheduling & Construction Accounting \& Finance \\
\hline 5 & Construction Law & $\begin{array}{l}\text { Construction Cost Estimation/Bidding } \\
\text { Strategy }\end{array}$ \\
\hline 6 & Construction Accounting \& Finance & $\begin{array}{l}\text { Construction Contracts } \\
\text { Administration/Business }\end{array}$ \\
\hline 7 & $\begin{array}{l}\text { Construction Planning and Cost } \\
\text { Control/Analysis }\end{array}$ & Facility Planning and Management \\
\hline 8 & Construction Safety Management & Construction Law \\
\hline 9 & Legal Issues in Construction & Construction Project Delivery Systems \\
\hline 10 & Construction Management Research & Seminar \\
\hline 11 & Construction Project Delivery Systems & Risk Management \\
\hline 12 & Seminar & Innovation in Construction \\
\hline 13 & $\begin{array}{l}\text { Advanced Computer Applications in } \\
\text { Construction }\end{array}$ & Construction Scheduling \\
\hline 14 & Leadership in Construction & $\begin{array}{l}\text { Construction Planning and Cost } \\
\text { Control/Analysis }\end{array}$ \\
\hline 15 & Codes \& Regulations & Graduate Internship \\
\hline 16 & $\begin{array}{l}\text { Construction Contracts } \\
\text { Administration/Business }\end{array}$ & Independent Study \\
\hline 17 & Graduate Internship & Construction Management Special Topics \\
\hline 18 & Independent Study & Leadership in Construction \\
\hline 19 & Construction Information Systems & Construction Visualization and Simulation \\
\hline 20 & Construction Delays and Claims & Construction Professional Competencies \\
\hline
\end{tabular}

However, the programs with leadership and upper-level management focus offer similar courses offered by the research-oriented programs. The evaluation of current CM-graduate programs across the country (as demonstrated in Table 2) supports the argument for the lack of senior management level content in construction management graduate education, even in the programs which have purpose statements with a focus on developing construction management leaders.

\section{Research Methodology}

To further determine if the findings of the curriculum analysis were consistent with industry demand, the authors distributed a survey to construction industry professionals. The focus of the survey was to identify if the courses listed in Leadership focused programs (Category 1 from Table 2) would help in developing senior-level construction management leaders. Delphi methodology was utilized in this study. The Delphi Technique is a systematic and iterative process used to collect the opinion of 
experts on a specific topic. The goal of the Delphi technique is to achieve consensus among a selected panel of experts. Delphi study is conducted in an anonymous environment. This will assist the participants in changing their previous opinions. The current study uses the classical Delphi approach, which has minimal impact on the reliability and validity of the data obtained.

Selection of Expert panel The participants in the Delphi study were considered content experts who have knowledge and experience about the issue being investigated (Skulmoski, Hartman, \& Krahn, 2007). Purposeful sampling was performed to ensure that the sample consists of individuals who are knowledgeable and experienced about the topic of senior-level or executive-level issues in the construction industry. Potential experts were selected from the contacts the research team has access to through national and regional associations and networks. Also, the snowball sampling technique helped the authors to find a few more experts. Three categories of experts were selected for this study i) Senior-level Managers or Construction Executives who have more than 15 years of experience in the industry, ii) Mid-Level Managers who have at least 5 years of experience in the construction industry, and iii) External industry members such as CPAs, Bankers, Sureties, Insurance Brokers who work closely with the construction industry. The reason for selecting this heterogeneous group of experts was to identify the perceptions of different stakeholders. This heterogeneity also assures the validity of the results (Hallowell \& Gambatese, 2009).

Delphi Survey The design of the study included a three-phased survey with the industry expert panel. The questionnaire for the demographic survey and phase one of the survey was developed by the research team prior to the beginning of the survey. The survey was conducted through an onlinebased survey program called Qualtrics. Participants were contacted through an e-mail from the Qualtrics. The demographic survey was sent in June 2019, and Phase 1 of the study was sent in September 2019. The questionnaire for Phase 2 was developed based on the responses from Phase 1, as is typical methodology for Delphi studies. Phase 2 was sent in October 2019. Previous research suggests that two rounds are adequate in a Delphi study when a structured instrument is used.

Consensus Criteria Consensus is defined as the collective opinion arrived by the research participants (Gough, 1987). Many of the previous Delphi studies set the consensus criteria as at least $75 \%$ of the participants responding to either agree or strongly agree on a 5-point Likert Scale. Few Delphi studies defined consensus as a 51\% agreement among the participants (Loughlin \& Moore, 1979). Selecting the consensus criteria is arbitrary in most of the previous studies (Flanders, 1988). Utilizing a 5-point scale is popular, but it restricts the participants' responses to just those 5 choices. To account for this problem, the authors utilized the 100-point scale where 100 represents strongly agree, and 0 represents strongly disagree. In selecting the consensus criteria for the 100-point scale, the authors carefully analyzed the previous criterion and set a higher standard for consensus. The authors defined consensus on agreement on an item as responding greater than or equal to 80 on a 100-point scale. Once each respondent completed each phase, the mean and median were established for each response category. The median was reported in the results section as it measures more accurate central tendency of the data. The mean was not used as limited respondents $(n=29)$, and the nature of a Delphi study does not allow for eliminating outliers without adversely impacting the results.

Consensus was achieved on an item in this study if at least $75 \%$ of the respondents were in agreement or responded with a score of 80 or greater than 80 on the 100-point scale. This condition also ensures that median would be greater than 80 . 


\section{Results and Discussion}

Phase 1 The 20 frequently offered courses in the leadership category identified from the literature were compiled and sent. Twenty-nine out of the 31 experts responded to the Phase 1 survey resulting in a 94\% response rate. The demographic distribution of the participants is presented in Table 3.

Demographic Data indicated that $93 \%$ of the participants possess a bachelor's degree or higher. More than 50\% of the participants work at a Director, Vice President, or a President role in their companies.

Three courses met the consensus criteria in Phase 1, indicating that these courses were relevant in developing senior-level managers in the construction industry. The remaining 17 courses did not meet the consensus criteria and were further pursued in Phase 2. The results from Phase 1 of the survey are presented in Table 4.

Table 3

Participants Demographic Data Table

\begin{tabular}{|c|c|c|}
\hline & Phase $1(n=29)$ & Phase $2(n=28)$ \\
\hline \multicolumn{3}{|l|}{ Position/ Job Category } \\
\hline Executives/ Senior-level & $76 \%$ & $75 \%$ \\
\hline Mid-level Manager & $14 \%$ & $14 \%$ \\
\hline External Industry & $10 \%$ & $11 \%$ \\
\hline \multicolumn{3}{|l|}{ Education } \\
\hline Bachelor's Degree & $65 \%$ & $64 \%$ \\
\hline Master's Degree & $28 \%$ & $29 \%$ \\
\hline No Degree & $7 \%$ & $7 \%$ \\
\hline \multicolumn{3}{|c|}{$\begin{array}{l}\text { Years of experience in the Current } \\
\text { role }\end{array}$} \\
\hline 1-5 Years & $42 \%$ & $39 \%$ \\
\hline 6-10 Years & $31 \%$ & $32 \%$ \\
\hline 11-15 Years & $10 \%$ & $11 \%$ \\
\hline$>15$ Years & $17 \%$ & $18 \%$ \\
\hline
\end{tabular}

Phase 2 Phase 2 questionnaire was sent to the 29 experts who responded to Phase 1. Delphi study allows for controlled feedback by informing the participants about the results of the previous phase. The results of the Phase 1 of the Delphi study was sent to the participants. This helped the participants to reflect on their answers in relation to the entire panel. The participants reconsidered or changed their responses during Phase 2 based on the collective group response from Phase 1.

As an addition to the current study, the authors were interested in identifying the most effective course delivery methods for teaching senior-level construction content. Delivery methods were not included in the Delphi study and thus excluded from Phase 2. Participants were asked to rate the effectiveness of 10 types of delivery methods, which the authors came up with after a brainstorming session. The results regarding the effectiveness of delivery methods were presented in Figure 1. Data for the delivery methods can be found in Appendix. 
Table 4

Results

\begin{tabular}{|c|c|c|c|c|}
\hline $\begin{array}{l}\text { Sl. } \\
\text { No }\end{array}$ & Course & Agreement & Median & $\begin{array}{l}\text { Consensus Status } \\
\text { (Phase) }\end{array}$ \\
\hline 1 & Construction Project Management & $86 \%$ & 90 & Achieved (1) \\
\hline 2 & Leadership in Construction & $86 \%$ & 90 & Achieved (1) \\
\hline 3 & Construction Scheduling & $82 \%$ & 85 & Achieved (2) \\
\hline 4 & Construction Accounting \& Finance & $79 \%$ & 85 & Achieved (2) \\
\hline 5 & $\begin{array}{l}\text { Construction Planning and Cost } \\
\text { Control/Analysis }\end{array}$ & $76 \%$ & 90 & Achieved (1) \\
\hline 6 & Legal issues in Construction & $75 \%$ & 80 & Achieved (2) \\
\hline 7 & $\begin{array}{l}\text { Construction Contracts } \\
\text { Administration/Business }\end{array}$ & $75 \%$ & 80 & Achieved (2) \\
\hline 8 & Construction Delays and Claims & $75 \%$ & 85 & Achieved (2) \\
\hline 9 & $\begin{array}{l}\text { Construction Cost Estimation/Bidding } \\
\text { Strategy }\end{array}$ & $71 \%$ & 85 & No Consensus \\
\hline 10 & Construction Safety Management & $71 \%$ & 80 & No Consensus \\
\hline 11 & Construction Project Delivery Systems & $64 \%$ & 80 & No Consensus \\
\hline 12 & Graduate Internship & $61 \%$ & 85 & No Consensus \\
\hline 13 & Construction Law & $57 \%$ & 80 & No Consensus \\
\hline 14 & Codes \& Regulations & $21 \%$ & 65.5 & No Consensus \\
\hline 15 & Construction Information Systems & $21 \%$ & 60 & No Consensus \\
\hline 16 & $\begin{array}{l}\text { Advanced Computer Applications in } \\
\text { Construction }\end{array}$ & $14 \%$ & 53 & No Consensus \\
\hline 17 & Sustainability and Green Construction & $11 \%$ & 50 & No Consensus \\
\hline 18 & Construction Management Research & $7 \%$ & 51 & No Consensus \\
\hline 19 & Seminar & $4 \%$ & 49 & No Consensus \\
\hline 20 & Independent Study & $4 \%$ & 30 & No Consensus \\
\hline
\end{tabular}

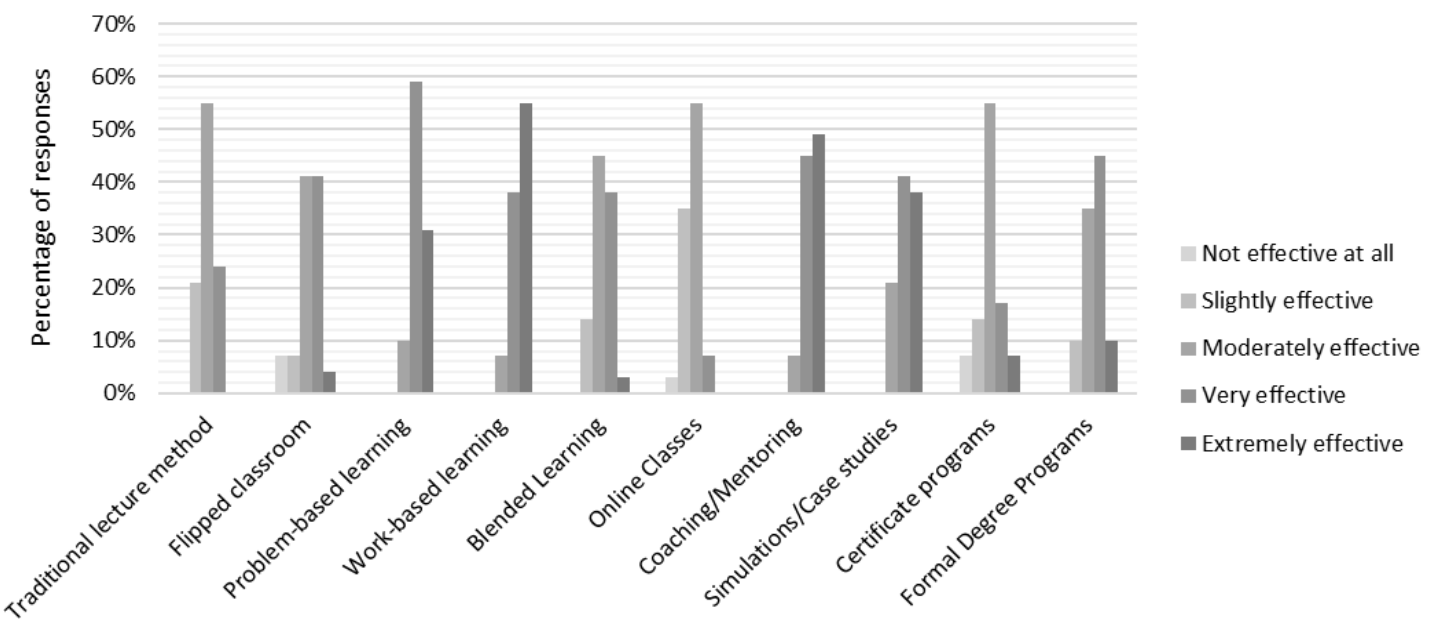

Figure 1: Delivery Methods 


\section{Conclusions}

Construction management graduate curriculums in the United States still have a more significant variation in the course-offerings when compared to undergraduate CM curriculums. Sustainability and Green Construction, and Building Information Modeling are two topics that have gained momentum in recent years and are reflected in the course offerings in Table 1. Also, it is surprising to see that Sustainability, which is the most frequently offered course across the 34 graduate programs to be one of the lowest preferences by the industry professionals. Work-based learning, Problem-based learning, and Coaching or Mentoring were perceived as the most effective delivery methods by the panel for senior-level education. It is interesting to note that Online Classes, which is one of the most popular choices for senior-level education to be perceived as the least effective delivery method by the panel.

In the present study, through a two-round Delphi study, the courses which are relevant to producing leaders in the construction industry are identified. The results of the study indicate that Construction Project Management, Leadership in Construction, Construction Scheduling, Construction Accounting and Finance, Construction Planning and Cost Control Analysis, Legal issues in Construction, Construction Contracts Administration, and Construction Delays and Claims met the consensus criteria. The results indicate that the current graduate-level construction management curriculums are not adequately focused on developing senior-level construction managers. The results reinforce the previous research findings that industry perceptions differ from what is being offered in academia (Lee, Ponton, Jeffreys, \& Cohn, 2011).

There is a need for collaboration between educators and construction industry professionals in developing master's programs that align with the needs of the construction industry. Forming an industry advisory committee is a smart way of incorporating industry's suggestions into the curriculum based on the evolving trends in the construction industry. Continuous curriculum revisions in response to the industry trends ensure graduating students to be equipped with the right skills for a successful career in construction.

\section{Limitations}

The results of the Delphi study are based on the subjective judgment of the expert panel, which might be prone to several biases. The authors mitigated this to some extent, by having a higher number of participants $(n=29)$ compared to the minimum panel requirement of 8 experts (Hallowell \& Gambatese, 2009). Also, anonymity is maintained to mitigate the dominance effect. The curriculum analysis was conducted on a reasonable sample of 34 graduate programs in this study. This was not inclusive of all CM graduate programs in the United States. However, all efforts were made to have a reasonable level of representation of program types, geographical locales, and curricula emphasis areas.

\section{References}

Arditi, D., \& Polat, G. (2010). Graduate Education in Construction Management. Journal of Professional Issues in Engineering Education and Practice, 136(3), 175-179. doi:10.1061/(ASCE)El.1943-5541.0000014 
Atalah, A., \& Muchemedzi, R. (2006). Improving Enrollment in the Master of Construction Management Program at Bowling Green State University. Journal of Professional Issues in Engineering Education and Practice, 132(4), 312-321. doi:10.1061/(ASCE)1052-3928(2006)132:4(312)

Flanders, F. (1988). Determining curriculum content for nursery/landscape course work in vocational agriculture for the twenty-first century: A futures study utilizing the Delphi technique. In A. A. Cross (Ed.): ProQuest Dissertations Publishing.

Goodman, R. E., \& Chinowsky, P. S. (1997). Preparing Construction Professionals for Executive Decision Making. Journal of Management in Engineering, 13(6), 55-61. doi:10.1061/(ASCE)0742-597X(1997)13:6(55)

Gough, N. (1987). Forecasting Curriculum Futures: Arts of Anticipation in Curriculum Inquiry.

Hallowell, M. R., \& Gambatese, J. A. (2009). Qualitative research: Application of the Delphi method to CEM research. Journal of Construction Engineering and Management, 136(1), 99-107.

Lee, N., Ponton, R., Jeffreys, A., \& Cohn, R. (2011). Analysis of industry trends for improving undergraduate curriculum in construction management education. Paper presented at the ASC Proceedings of the 47th Annual International Conference, Omaha, NE.

Loughlin, K. G., \& Moore, L. F. (1979). Using Delphi to achieve congruent objectives and activities in a pediatrics department. Journal of medical education, 54(2), 101-106.

Popescu, C. (1987). Construction Engineering Graduate Education Survey. Journal of Construction Engineering and Management, 113(4), 664-668. doi:10.1061/(ASCE)0733-9364(1987)113:4(664)

Skulmoski, G. J., Hartman, F. T., \& Krahn, J. (2007). The Delphi Method for Graduate Research. Journal of Information Technology Education, 6, 1-21.

\section{Appendix}

Data for Delivery Methods: The percentages represents the number of participants who rated that particular effectiveness.

\begin{tabular}{|l|r|r|r|r|r|r|}
\hline & Not effective at all & Slightly effective & Moderately effective & Very effective & Extremely effective \\
\hline Traditional lecture method & $0 \%$ & $21 \%$ & $55 \%$ & $24 \%$ & $0 \%$ \\
\hline Flipped classroom & $7 \%$ & $7 \%$ & $41 \%$ & $41 \%$ & $4 \%$ \\
\hline Problem-based learning & $0 \%$ & $0 \%$ & $10 \%$ & $59 \%$ & $31 \%$ \\
\hline Work-based learning & $0 \%$ & $0 \%$ & $7 \%$ & $38 \%$ & $55 \%$ \\
\hline Blended Learning & $0 \%$ & $14 \%$ & $45 \%$ & $38 \%$ & $3 \%$ \\
\hline Online Classes & $3 \%$ & $35 \%$ & $55 \%$ & $7 \%$ & $0 \%$ \\
\hline Coaching/Mentoring & $0 \%$ & $0 \%$ & $7 \%$ & $45 \%$ & $49 \%$ \\
\hline Simulations/Case studies & $0 \%$ & $0 \%$ & $21 \%$ & $41 \%$ & $38 \%$ \\
\hline Certificate programs & $7 \%$ & $14 \%$ & $55 \%$ & $17 \%$ & $7 \%$ \\
\hline Formal Degree Programs & $0 \%$ & $10 \%$ & $35 \%$ & $45 \%$ & $10 \%$ \\
\hline
\end{tabular}

